\title{
23. Abundance of Molecules in Stellar Atmospheres
}

\author{
By Takashi Tsuji \\ Department of Astronomy, University of Tokyo \\ (Comm. by Yusuke HagiharA, M.J.A., Feb. 12, 1964)
}

1. The knowledge of the physical states in stellar atmospheres is highly required for interpreting the observed characteristics of the stellar spectra. Accordingly, it seems quite natural to think that in cool stars the observed spectral features are essentially related with molecular dissociation in stellar atmospheres. That is to say, the study of the dissociation equilibria is the basis of our understanding of the atmospheres of late type stars, especially, of $\mathrm{M}, \mathrm{S}$, and $\mathrm{C}$ type stars. The first comprehensive study on this problem was that by Russell ${ }^{1}$ who showed that the observed molecular feature in cool stars can reasonably be understood on the basis of the dissociation theory. Next important studies on this problem were those by Fujita $^{2}$, who emphasized the importance of $\mathrm{H}: \mathrm{C}: \mathrm{N}: \mathrm{O}$ abundance ratio for the spectral branching in cool stars. $\mathrm{He}$ has also shown that $\mathrm{O} / \mathrm{C}$ ratio is an important factor to distinguish the physical characteristics between $\mathrm{M}$ and $\mathrm{S}$ type stars. In recent years, de Jager and $\mathrm{Neven}^{3)}$ have treated this problem with the modern values of molecular constants. Though the gross feature of the molecular spectra were understood by these works, still further studies should be indispensable by the following reasons: First, there is no a priori reason why we can confine our attention only to diatomic molecules and $\mathrm{H}_{2} \mathrm{O}$. Indeed, $\mathrm{C}_{3}$ and $\mathrm{SiC}_{2}$ were identified in cool carbon stars and this fact suggests the predominance of more stable polyatomic molecules. Second, some of the molecular features in stars are not fully satisfactorily understood yet. For example, the well known observation that $\mathrm{C}_{2}$ intensities in carbon stars go through maximum at C5 spectral type has not been accounted for. This fact indicates that our understanding of the physical state in cool stars is still unsatisfactory. Third, for the quantitative study of various types of cool stars, detailed computations of molecular abundance for variety of values of $\mathrm{H}: \mathrm{C}: \mathrm{N}: \mathrm{O}$ ratio are required.

2. We evaluated the dissociation constants of about hundred molecules, the most important compounds of which are given in Table I together with the dissociation energies adopted. The equilibrium compositions of forty-four molecules composed of $\mathrm{H}, \mathrm{C}, \mathrm{N}$, and $\mathrm{O}$ atoms were $_{\text {calculated }}^{*)}$ for sixteen sets of values of $\mathrm{H}: \mathrm{C}: \mathrm{N}: \mathrm{O}$ ratio which

\footnotetext{
*) The computations were performed by the electronic computor, OKITAK 5090, of the Computation Center, University of Tokyo.
} 
Table I. Dissociation energies adopted

\begin{tabular}{|c|c|c|c|c|c|}
\hline Binding & $\mathrm{D}(\mathrm{ev})$ & Binding & $\mathrm{D}(\mathrm{ev})$ & Binding & $\mathrm{D}(\mathrm{ev})$ \\
\hline $\mathrm{H}-\mathrm{H}$ & 4.476 (a) & C-C & 6.12 (f) & $\mathrm{N}-\mathrm{H}$ & 3.8 (a) \\
\hline $\mathrm{O}-\mathrm{H}$ & 4.40 (a) & $\mathrm{C}_{2}-\mathrm{H}$ & $5.72(\mathrm{e})$ & $\mathrm{NH}-\mathrm{H}$ & 3.76 (h) \\
\hline $\mathrm{HO}-\mathrm{H}$ & $5.10(b)$ & $\mathrm{C}_{2} \mathrm{H}-\mathrm{H}$ & $4.95 \quad(\mathrm{e})$ & $\mathrm{NH}_{2}-\mathrm{H}$ & $4.51(\mathrm{~h})$ \\
\hline $0-0$ & $5.115(\mathrm{a})$ & $\mathrm{C}_{2} \mathrm{H}_{2}-\mathrm{H}$ & $1.69 \quad(\mathrm{e})$ & $\mathrm{C}-\mathrm{N}$ & 8.2 (a) \\
\hline $\mathrm{C}-\mathrm{O}$ & $11.090(\mathrm{a})$ & $\mathrm{C}_{2} \mathrm{H}_{3}-\mathrm{H}$ & $4.51 \quad(\mathrm{e})$ & $\mathrm{H}-\mathrm{CN}$ & $4.95(i)$ \\
\hline $\mathrm{CO}-\mathrm{O}$ & $5.45(\mathrm{~b})$ & $\mathrm{C}_{2}-\mathrm{C}$ & 7.74 (f) & $\mathrm{CN}-\mathrm{CN}$ & $4.86(\mathrm{j})$ \\
\hline $\mathrm{H}-\mathrm{CO}$ & 1.17 (c) & $\mathrm{C}_{3}-\mathrm{H}$ & $4.92(\mathrm{~g})$ & $\mathrm{C}_{2}-\mathrm{N}$ & $8.13(\mathrm{k})$ \\
\hline $\mathrm{N}-\mathrm{N}$ & 9.758 (a) & $\mathrm{C}_{3} \mathrm{H}-\mathrm{H}$ & $3.12(\mathrm{~g})$ & $\mathrm{C}_{3}-\mathrm{N}$ & $7.39 \quad(\mathrm{k})$ \\
\hline $\mathrm{C}-\mathrm{H}$ & 3.47 (a) & $\mathrm{C}_{3} \mathrm{H}_{2}-\mathrm{H}$ & $3.51(\mathrm{~g})$ & $\mathrm{H}-\mathrm{C}_{3} \mathrm{~N}$ & $3.97(\mathrm{k})$ \\
\hline $\mathrm{CH}-\mathrm{H}$ & $4.35 \quad(d)$ & $\mathrm{C}_{3}-\mathrm{C}$ & $5.21(\mathrm{~g})$ & $\mathrm{N}-\mathrm{O}$ & $6.503(\mathrm{a})$ \\
\hline $\mathrm{CH}_{2}-\mathrm{H}$ & $4.80 \quad(d)$ & $\mathrm{C}_{4}-\mathrm{H}$ & $5.90(\mathrm{~g})$ & SiC-C & $8.7 \quad(1)$ \\
\hline $\mathrm{CH}_{3}-\mathrm{H}$ & 4.38 (e) & $\mathrm{C}_{4} \mathrm{H}-\mathrm{H}$ & $4.09(\mathrm{~g})$ & & \\
\hline
\end{tabular}

(a) G. Herzberg, Ref. (9).

(b) F. D. Rossini et al.: Circ. N. B. S., 500 (1952).

(c) K. Klein and L. J. Schoen: J. Chem. Phys., 24, 1094 (1956).

(d) H. Prophet: J. Chem. Phys., 38, 2345 (1963).

(e) B. E. Knox and H. B. Palmer: Chem. Rev., 61, 247 (1961).

(f) J. Drowart et al.: J. Chem. Phys., 31, 1131 (1959).

(g) M. Cowperthwaite and S. H. Bauer: J. Chem. Phys., 36, 1743 (1962).

(h) A. P. Altshuller: J. Chem. Phys., 22, 1947 (1954).

(i) C. A. McDowell and J. M. Warren: Trans. Farad. Soc., 48, 1084 (1952).

(j) W. Tsang et al.: J. Chem. Phys., 36, 1768 (1962).

(k) V. H. Dibeler et al.: J. Am. Chem. Soc., 83, 1813 (1961).

(1) J. Drowart et al.: J. Chem. Phys., 29, 1015 (1958).

may cover the possible abundance ratio in cool stars such as M, MS, $\mathrm{S}, \mathrm{SC}, \mathrm{C}, \mathrm{CH}$, and hydrogen deficient stars. The computations were performed for the range of $\Pi=0.6 \sim 5.0$ and $\log \mathrm{Pg} \simeq-3.0 \sim 8.0$ to be used for the quantitative analysis of stellar spectra, for the investigation of the atmospheric structures and also for the studies of the physical characteristics of cool stars as well as of general astrophysical problems. In what follows, we shall discuss briefly the main results.*

3. We shall first discuss the equilibria in carbon rich stars. Fig. 1 shows the result for the abundance ratio of $\mathrm{H}: \mathrm{C}: \mathrm{N}: \mathrm{O}=10^{3}: 5$ : $5: 1$ and $\log \mathrm{Pg} \sim 3.0$. It should be noted that the polyatomic species such as $\mathrm{HCN}, \mathrm{C}_{2} \mathrm{H}$ and $\mathrm{C}_{2} \mathrm{H}_{2}$ etc. are more abundant than diatomic ones such as $\mathrm{CN}, \mathrm{CH}$, and $\mathrm{C}_{2}$ especially below $2800^{\circ} \mathrm{K}$. Though not shown in the figure, other species such as $\mathrm{C}_{2} \mathrm{~N}, \mathrm{C}_{3} \mathrm{~N}, \mathrm{HC}_{3} \mathrm{~N}$ and many

*) The details of the calculated results and their discussion in connection with observations, together with the discussions on molecular constants adopted, will be published in Annals of the Tokyo Astronomical Observatory. 


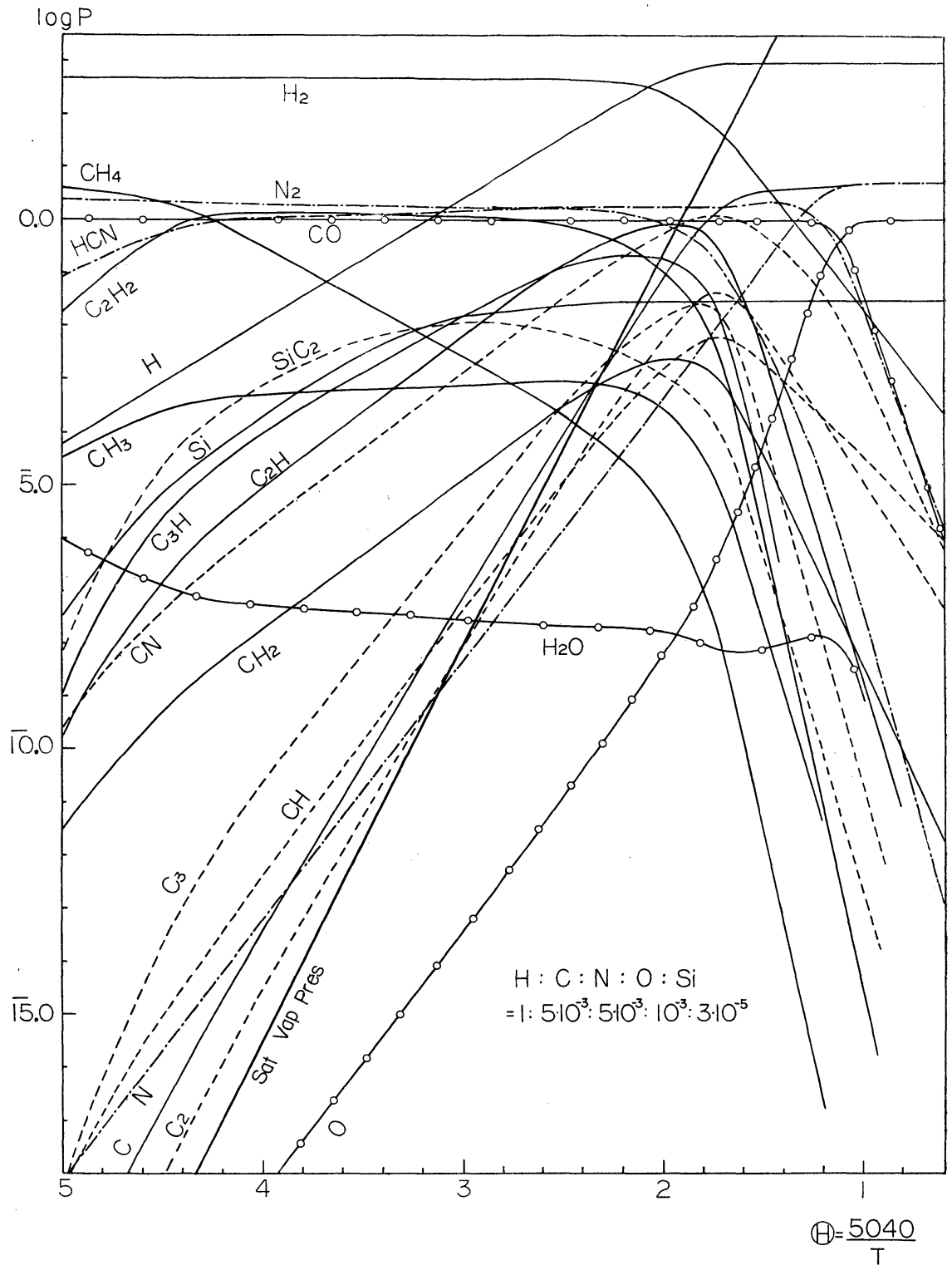

Fig. 1. The equilibrium composition in carbon rich giants (log Pg 2.0 ). The logarithm of the partial pressure of atoms and molecules is plotted against $\mathbb{1}=5040 / \mathrm{T}$. 
hydrocarbons are also conspicuous. The overall feature of molecular equilibria is essentially controlled by polyatomic molecules rather than by diatomic ones in cool carbon stars.

It is interesting to note that $\mathrm{C}_{2}$ concentration goes through maximum at about $2800^{\circ} \mathrm{K}$, which may correspond to C5 spectral class. This fact can be regarded as the final justification to show the validity of C-classification by Keenan and Morgan ${ }^{4)}$ as a temperature class. The concentration of $\mathrm{C}_{3}$ molecules to which one ascribes the source of enormous absorption in ultraviolet region of the spectra in cool carbon stars has also maximum at about $2800^{\circ} \mathrm{K}$. This result offers the natural explanation to the observed fact that the so-called ultraviolet depression is by no means most intense in the coolest carbon stars but rather intense at C5 C6 spectral classes. ${ }^{5)}$ The reason why $\mathrm{C}_{2}$ and $\mathrm{C}_{3}$ concentrations pass through maximum at about $2800^{\circ} \mathrm{K}$ is that the free carbons are largely depleted by $\mathrm{HCN}, \mathrm{C}_{2} \mathrm{H}$, and $\mathrm{C}_{2} \mathrm{H}_{2}$ etc. below $2800^{\circ} \mathrm{K}$. In this way, the molecular features of carbon stars are reasonably understood and this fact in turn is an indirect evidence to indicate the importance of polyatomic species not yet observed directly.

At high temperature, partial pressure of free carbon is proportional to gas pressure but, below $2800^{\circ} \mathrm{K}(\log \mathrm{Pg} \sim 3.0)$, it is almost independent of total gas pressure. This fact can be understood by the strengthened depletion of carbon atoms by $\mathrm{HCN}$ and $\mathrm{C}_{2} \mathrm{H}_{2}$ etc. at higher gas pressures. Then, the mass fraction of $\mathrm{C}_{2}$ is larger for low luminosity at later C-type stars while smaller at early C-type stars. This fact will produce complicated absolute magnitude effect in observed $\mathrm{C}_{2}$ intensities. The $\mathrm{C}_{2}$ concentration is influenced by $\mathrm{C} / \mathrm{O}$ ratios as was expected and our calculations for various $\mathrm{N} / \mathrm{C}$ ratios for fixed $\mathrm{H}: \mathrm{C}: \mathrm{O}$ ratio also produces large scattering in $\mathrm{C}_{2}$ concentrations. ${ }^{*}$ In this way, the interpretation of the second parameter of C-classification by Keenan and Morgan ${ }^{4)}$ which was tentatively ascribed to the variations of $\mathrm{C} / \mathrm{O}$ ratio, must be reinterpreted in future in terms of $\mathrm{H}: \mathrm{C}: \mathrm{N}: \mathrm{O}$ ratio and luminosity.

In Fig. 1 is also shown the concentration of $\mathrm{SiC}_{2}$ which was identified as the carrier of the so-called MS bands. ${ }^{6)}$ Though not shown in the figure, we have considered fifteen silicon compounds**) to

*) If $\mathrm{N} / \mathrm{C}>1$, carbon atoms are largely depleted by $\mathrm{HCN}$ and $\mathrm{C}_{2}$ concentration suffers large depletion while if $\mathrm{N} / \mathrm{C}<1$, carbon atoms are no longer so strongly depleted by highly stable HCN but partial pressure of free carbon is mainly controlled by the equilibrium of hydrocarbons such as $\mathrm{C}_{2} \mathrm{H}, \mathrm{C}_{2} \mathrm{H}_{2}$, and $\mathrm{C}_{3} \mathrm{H}$. It is also remarked, however, that the temperature at which $\mathrm{C}_{2}$ concentration attains maximum is almost independent of $\mathrm{H}: \mathrm{C}: \mathrm{N}: \mathrm{O}$ ratio so long as $\mathrm{C}>\mathrm{O}$ but depends only on total gas pressures.

**) These are $\mathrm{SiH}, \mathrm{SiH}_{2}, \mathrm{SiH}_{3}, \mathrm{SiH}_{4}, \mathrm{SiC}, \mathrm{SiC}_{2}, \mathrm{Si}_{2} \mathrm{C}, \mathrm{Si}_{2} \mathrm{C}_{2}, \mathrm{Si}_{2} \mathrm{C}_{3}, \mathrm{Si}_{3} \mathrm{C}_{2}, \mathrm{SiN}, \mathrm{SiO}$, $\mathrm{SiO}_{2}, \mathrm{Si}_{2}$, and $\mathrm{Si}_{3}$. 
evaluate the concentration of $\mathrm{SiC}_{2}$. However, the results seem to be in contradiction with observations which show the decrease of MS band intensities for later C-type stars. ${ }^{7}$ It is supposed that some unknown stable compounds such as $\mathrm{HSiN}$, and $\mathrm{Si}_{2} \mathrm{H}_{2}$ etc. are present in carbon stars to deplete the silicon atoms in later C-type stars.

The straight line in Fig. 1 represents the saturated vapour pressure of graphite. ${ }^{8)}$ The partial pressure of free carbon exceeds the saturated vapour pressure of graphite at about $2200^{\circ} \mathrm{K}$. This fact opens the possibility of precipitation of graphite particles. The equilibrium shown in Fig. 1 is a kind of pseudo equilibrium in which free carbon is supersaturated. At the strict thermal equilibrium, carbon atoms are condensed in graphite until partial pressure of free carbon is reduced to the value of saturated vapour pressure. Then, the concentrations of molecules containing carbon atoms which were in equilibrium with free carbon also suffer the large depletions.*)

4. For oxygen rich stars, the essential feature of molecular equilibria is not radically altered from those hitherto considered. Here, $\mathrm{H}_{2} \mathrm{O}$ plays decisive role below $2500^{\circ} \mathrm{K}(\log \mathrm{Pg} \sim 3.0)$. For $\mathrm{M}$ dwarf stars, however, polyatomic species such as $\mathrm{CH}_{2}, \mathrm{CH}_{3}, \mathrm{CH}_{4}, \mathrm{NH}_{2}$, $\mathrm{HCO}, \mathrm{HCN}$, and $\mathrm{CO}_{2}$ etc. are conspicuous, and at $\log \mathrm{Pg} \sim 6.0$ and $\mathrm{NH}_{3}, \mathrm{~T} \sim 1000^{\circ} \mathrm{K}$, carbon atoms are depleted by $\mathrm{CH}_{4}$ rather than by $\mathrm{CO}$ even though $\mathrm{O}>\mathrm{C}$.

5. It is shown that polyatomic molecules are more important than those hitherto considered, especially in the atmospheres of cool carbon stars. It is evident that no consideration on dissociation equilibria in stellar atmospheres can be satisfactory which do not properly incorporate the part played by the polyatomic molecules. As forty-four molecules composed of $\mathrm{H}, \mathrm{C}, \mathrm{N}$, and $\mathrm{O}$ atoms were considered, we may not be far from reality so long as the equilibria of compounds composed of $\mathrm{H}, \mathrm{C}, \mathrm{N}$, and $\mathrm{O}$ atoms are concerned.

One may regard our results still of preliminary character in that the abundance of $\mathrm{H}, \mathrm{C}, \mathrm{N}$ and $\mathrm{O}$ atoms are not known at present. However, it should be emphasized that one of the very purposes of our study of molecular equilibria is to offer the basis of the quantitative analysis of molecular spectra by which the knowledge on abundance should be obtained.**)

*) At strict thermal equilibrium, below $2200^{\circ} \mathrm{K}$, about $80 \%$ of carbon atoms are condensed in graphite, about $20 \%$ of carbons remain in $\mathrm{CO}$ molecules and very small fraction of total carbons are distributed among various compounds, which are in equilibrium with the free carbons, the concentration of which corresponds to saturated vapour pressure.

**) If one is to try to determine, for example, the $\mathrm{N} / \mathrm{C}$ ratio in carbon stars from the observed $\mathrm{CN} / \mathrm{C}_{2}$ ratio, as the concentrations of $\mathrm{CN}$ and $\mathrm{C}_{2}$ are influenced in complicated fashion by $\mathrm{H}: \mathrm{C}: \mathrm{N}: \mathrm{O}$ ratio through the depletions of $\mathrm{H}, \mathrm{C}, \mathrm{N}$, and $\mathrm{O}$ atoms by unobservable molecules such as $\mathrm{CO}, \mathrm{N}_{2}, \mathrm{HCN}$, and $\mathrm{C}_{2} \mathrm{H}_{2}$ etc., one must carefully compare the detailed calculations for many sets of values of $\mathrm{H}: \mathrm{C}: \mathrm{N}: \mathrm{O}$ ratio with observations. 
Our results show the predominance of polyatomic molecules in cool stars. However, the polyatomic compounds so far identified are only $\mathrm{SiC}_{2}$ and $\mathrm{C}_{3}$. As was discussed by Herzberg, ${ }^{9)}$ the electronic spectra of polyatomic free radicals can possibly by observed in the visible spectral regions. It must be interesting to examine the identifications of abundant free radicals such as $\mathrm{CH}_{2}, \mathrm{C}_{2} \mathrm{H}, \mathrm{C}_{3} \mathrm{H}, \mathrm{C}_{2} \mathrm{~N}$, and $\mathrm{C}_{3} \mathrm{~N}$ etc. in carbon stars as well as $\mathrm{NH}_{2}, \mathrm{HCO}$, and $\mathrm{CH}_{2}$ etc. in M-dwarf stars.

In view of the astrophysical significance, however, much attention should be directed to the rotation-vibration bands of polyatomic molecules in infrared region. As was pointed out by Wildt, ${ }^{10)} \mathrm{com}$ plex band absorptions aroused by many combinations of fundamentals as well as harmonics of molecular vibration of polyatomic molecules dominate the infrared region where large portion of the radiation flux of cool stars is concentrated, and hence the blanketing effect by them will play an essential role in determining the structure of stellar atmospheres. These effects may be important especially below $2800^{\circ} \mathrm{K}$ in giant stars. For $M$ type stars, Yamashita ${ }^{11}$ has shown that the blanketing effect by $\mathrm{H}_{2} \mathrm{O}$ is indeed important especially in late $\mathrm{M}$ stars. For carbon stars, polyatomic species are more numerous than in $\mathrm{M}$ stars and the blanketing effect by them, especially by $\mathrm{HCN}$, $\mathrm{C}_{2} \mathrm{H}_{2}, \mathrm{CH}_{4}$, and other hydrocarbons should be very important. If graphite particles are precipitated, they will also be important as a source of opacity. For exploring the atmospheres of carbon stars, much works must be done both in laboratory physics as well as in astrophysical observations and the roles played by the polyatomic molecules and by graphite particles should be clarified.

In conclusion, the author wishes to express his sincere gratitude to Prof. Y. Fujita for his valuable advices and encouragement throughout the work. He is also grateful to Drs. Y. Yamashita and F. Kamijo for stimulating discussions.

\section{References}

1) H. N. Russell: Ap. J., 79, 317 (1934).

2) Y. Fujita: Jap. Jour. Astr. and Geophys., 13, 21 (1935); 17, 17 (1939); 18, 45 (1940); 18, 177 (1941): P. A. S. Japan, 1, 171 (1950).

3) C. de Jager and L. Neven: Mém. Soc. R. Sc. Liège, 18, 357 (1957).

4) P. C. Keenan and W. W. Morgan: Ap. J., 94, 501 (1941).

5) A. Mckellar and E. H. Richardson: Mém. Soc. R. Sc. Liège 15, 256 (1955).

6) B. Kleman: Ap. J., 123, 162 (1956).

7) J. Humblet and G. Mannino: Ann. d' Ap., 18, 321 (1955).

Y. Fujita et al.: Publ. Dom. Astr. Obs., in press.

8) K. S. Pitzer and E. Clementi: J. Am. Chem. Soc., 81, 4778 (1959).

9) G. Herzberg: Mém, Soc. R. Sc. Liège, 18, 397 (1957).

10) R. Wildt: Mém. Soc. R. Sc. Liège, 18, 319 (1957).

11) Y. Yamashita: P. A. S. Japan, 14, 390 (1962). 